\title{
The Panacea and Perfidy of Culture As A Platform of Behaviour Change with Examples from Botswana and South Africa
}

\author{
Prof. S. M Kang'ethe \\ University of Fort Hare, Department of Social Work and Social Development \\ Box X1314, ALICE. 5700, South Africa \\ Email: kangethe@ufh.ac.za
}

\section{Doi:10.5901/mjss.2014.v5n14p504}

\section{Abstract}

The aim and of this article is to discuss the panacea and perfidy of cultures as a platform of positive behaviour change; as well as a deterrent to achieving HIVIAIDS/STI prevention objectives. Cultures can be a panacea through: exploiting rites of passage; using music, poetry and drama; using traditional leadership in the HIVIAIDS dissemination; strengthening cultural mores and taboos on sex; and exploiting languages to mainstream HIVIAIDS messages. Cultures can also be perfidious through: using it to oppress female gender empowerment; strengthening beliefs in unscientific and untested medical therapies; discouraging the use of condom; condoning wife inheritance; strengthening religions that are anti-prevention; giving traditional medical practitioners a platform to hide and give misleading HIVIAIDS messages; and condoning multiple and concurrent partnership (MCP). The article recommends the following: policy makers, behavioural change architects to take advantage of the immense social capital embedded in cultures and use it as a thrust for positive behavioural change; staging immense advocacy and lobbying mechanism to resuscitate positive prevention friendly aspects of cultures; and discarding aspects of cultures that are prevention unfriendly; and endeavour to make them human rights compliant.

Keywords: HIVIAIDS Prevention efforts, male circumcision (MC), cultural custodians, cultural mores and taboos, wife inheritance, patriarchy, traditional healers, multiple and concurrent partners (MCP), setswana proverbs

\section{Article Rationale}

The article, based on literature review, offers debate, discourse, and is a discursive platform to emphasize the importance of some aspects of culture that aid in strengthening prevention against STI such as HIVIAIDS; as well as identifying cultural aspects that could be weakening prevention. It has therefore identified and interrogated aspects of culture or its environment that compromise prevention efforts of STIs and HIVIAIDS.

\section{Operational Definition}

The word panacea which means an answer or solution for all problems or difficulties is operationally taken to mean a phenomenon which is satisfactory and desirable; while the word perfidy that refers to a state of deception, disloyal or treachery has been operationalised to mean a bad or undesirable state of affairs.

Bogwera and Bojale are respectively the male and female cultural schools of circumcision in Botswana

\section{Introduction}

As HIVIAIDS continue to pose both health and developmental challenges in developing countries, and the pursuit to look for a cure through immense experimentation process, the appropriate answer in this researcher's opinion remains and could be located on meaningful behaviour change (Ramphele, 2008; Treatment Action Campaign (TAC), 2007). However, behaviour change is a complex and a multifaceted phenomenon. This is because of the circumstances under which behaviour hinge. Perhaps winning the strategy of achieving a desirable behaviour change would be to lay bare all the possible underlying factors that inform a certain behavioural pattern; as well as those that pose a challenge to its change (Fisher \& Fisher, 2000). This calls for an examination of the cultures, traditions and customs that inform community socialization as well as a particular behavioural dispensation (Afolayan, 2004; Kang'ethe, 2009a). This researcher hypothesizes that not enough has been done to interrogate cultures and the immense social capital embedded in them to determine how they can be a thrust in the HIVIAIDS prevention; how they are a deterrent to 
prevention; and how their retrogressive aspects of them can be augmented to be prevention friendly (Kang'ethe, 2013). These propositions form the backbone of this article.

\section{Panacea of Cultures in Strengthening Prevention of HIV/AIDS}

\subsection{Rites of passage as forums of STI/HIV/AIDS message mainstreaming}

When cultural norms facilitate the process of bringing people together for some ceremonies such as the cultural rites of passage, this forms an opportunity of mainstreaming STI/HIVIAIDS messages without significantly tilting or changing the agenda or the meaning embedded in such ceremonies (Kang'ethe, 2013). To this end, the Botswana government has successfully negotiated and convinced the cultural custodians among the Bakgatla ba Kgafela ethnic group to include a prevention agenda in their circumcision school of bogwera (for men) and bojale (for females) (Government of Botswana (GOB), 2009a). This means that prevention will enjoy the blessings of the rich social capital embedded in such rites of passage (Kang'ethe, 2013).

Since the 2003 Kwazulu Natal clinical research found out that the males who get circumcised are $60 \%$ resilient to HIVIAIDS, the international community has staged a strong campaign urging the countries which are gravely affected by HIVIAIDS to consider adopting circumcision as one of the HIVIAIDS prevention campaign agenda (Peltzer, Nqeketo, George, \& Xola, 2008). To this end, many African countries have obliged to honour the call. In Botswana, although only the ethnic group of Bakgatla ba Kgafela has been practising the cultural norm of circumcision (although the practice had died and was only resuscitated in 2009), the government, through the funding of international aid agencies such as PEPFAR (President's Emergency Plan for HIVIAIDS Relief) has accelerated the campaign on male circumcision. The campaign is, however, paying great dividends with Batswana from all the corners of the country opting to undergo the circumcision, not only for cultural benefit, but as a HIVIAIDS prevention campaign response. And this has been easy in that the Bakgatla ba Kgafela ethnic group has provided a forum in which the government has afforded to mainstream and launch the HIVIAIDS prevention messages (GOB, 2009a).

Among the members of the Bakgatla tribe, and under the cooperation and coordination of their cultural custodians such as the chiefs, the male initiates attending bogwera; and the female initiates attending bojale schools of initiation have agreed to be tested and get pre and post counselling as part of the agenda of the rite. Further, the males instead of getting circumcised in the traditional way in the bush have obliged to have it done by the modern biomedical practitioners in the clinics. The cultural forum, therefore, has become a forum of prevention, without necessarily and significantly changing the goal posts; as well as the meaning and social capital embedded in the cultural norm of circumcision (GOB, 2009a; Kang'ethe, 2013).

\subsection{Traditional music, poetry and drama as forums of HIVIAIDS prevention}

Traditional music, poetry and drama are arts that every Motswana adores and like to participate in (Mathangwane, 2009; Mogogi, 2001). To this end, virtually all the schools in Botswana have traditional music clubs, poetry or drama groups to honour their culture, such as reinforcing the importance of living and maintaining peace among the communities, displaying love and being of use to one another (botho) (Mogogi, 2001; Kang'ethe \& Rhakudu, 2010). In an endeavour to have aspects of culture patented and recognised globally, the government in 2009 consulted UNESCO to delineate and patent its culture in the international cultural shelves. This is to ensure that aspects of culture, art and poetry peculiar to Batswana are protected from piracy by other countries. To say the least, Botswana has many cultural attraction sites that are considered UNESCO sites. This includes Tsodilo hills with paintings believed to indicate ancient people and how they were living (Campbell, Robbins \& Taylor, 2010). With the advent of HIVIAIDS, cultural phenomenon embedded in traditional music, poetry and drama forums' goal posts have been slightly tilted to accommodate the HIVIAIDS message mainstreaming and dissemination in Botswana (Mathangwane, 2009; Kang'ethe, 2013).

Under the auspices and patronage of Botswana National Youth Council (BNYC), many district cultural activities in Botswana entails organizing youth traditional dancers to stage in many of the national and international HIVIAIDS forums in the country. Such forum includes the Candlelight Memorial and World AIDS Day. While candlelight light Memorial Day remembers all the people who have died of HIVIAIDS since the advent of the epidemic, the World AIDS Day is a World Health Organization HIVIAIDS campaign day that is observed in early December by most countries of the world (Kang'ethe, 2010). In these commemorations, the use of traditional cultural and traditional dances, drama and poetry are widely employed in Botswana (DMSAC, 2005).

In the Southern District of Botswana, for instance, Baga- Mokgalo -Thebe traditional dancers have been going to 
schools to disseminate HIVIAIDS messages through their drama and poetry stage and dance performance. These cultural dances and groups also serve as recreational avenues. In some instance, the District HIVIAIDS offices through their operational organ, District Multisectoral AIDS committees (DMSACs) have been financing these youth cultural dancers in order to help in the mainstreaming and dissemination of the HIVIAIDS messages (DMSAC, 2005).

The use of media has also been critical in the HIVIAIDS arena. One recent initiative has been the development of a radio drama, Makgabaneng, that deals with culturally specific HIVIAIDS-related issues and encouraging changes in sexual behaviour. This has attracted audience as well as participation from people across all ages (NACA, 2005).

\subsection{Sustaining traditional leadership can be a stronger forum for HIV/AIDS dissemination}

In many countries, including Botswana, the traditional way of life is waning as cultures melt away and succumb to forces of modernization, westernization and globalization (Mogogi, 2001; Kang'ethe, 2006). In Botswana, although the power of the traditional leaders has been weakening as the central government centralizes power around itself, the role of the traditional chiefs ( dikgosis) still form an important part of the life of the Batswana. All the villages and wards are administratively led by the traditionally ordained chiefs and headmen. The dikgosis have their own parliament, the house of dikgosis (ntlo ya dikgosi). The role of house of chiefs is critical in that before all the constitutional amendments for the country are to be made by the government, they have to be assented to by the chiefs. This has meant that Botswana believes in the cultural way of advancing Batswana lives.

Culturally, decisions made by the chief and his henchmen at the chief's meeting place or kgotla have always been respected by the communities. To this end, the use of Kgotla has increasingly become an important forum for advancing and disseminating HIVIAIDS messages. In this author's HIVIAIDS campaigns in Botswana in the Southern District of Botswana, most of the HIVIAIDS community messages were taught and mainstreamed from the dikgotlas. The chiefs were, and still are important members of either the District Multisectoral AIDS Committee (DMSACS) or Sub District Multisectoral AIDS committee (Sub DMSACs); while headmen were also respected chairpersons of the Village Multisectoral AIDS committees (VMSACs). This author bears witness that in the 29 villages of the Southern Districts he staged HIVIAIDS campaign education in the year 2004-2005, the chairpersons of the VMSACS were the village headman (Bathusa dikgosi) (DMSAC Reports, 2005). Pivotally, mainstreaming HIVIAIDS education through these structures is to exploit the social capital embedded in these cultural forums (Kang'ethe, 2013).

\subsection{Cultures reinforcing the observance of taboos and sexual mores on chastity}

It is a panacea if the traditional cultural mores and taboos can discourage adolescent sexual engagements; encourage abstinence before marriage; and put restrictions on permissiveness in taking alcohol excessively and other illicit drugs. This is because of the huge risks that sexual indulgence; and excessive drinking apparently put people into, that of contracting both STIS and HIVIAIDS; as well as killing many people through road carnage. It is due to ardent and panacea of culture that this author supports the culturally ordained practices such as virginity testing among some communities in South Africa, Lesotho and Swaziland. Unfortunately in South Africa, virginity testing is being vigorously opposed by human rights bodies and NGOS. However, this author see nothing wrong in maintaining these culturally ordained practices for the sake of moral chastity and as a response to STI and HIVIAIDS prevention (Kang'ethe \& Gaseitsiwe, 2012). The human rights phenomenon and cultural rights have to be negotiated wisely in the spirit of fighting HIVIAIDS (Afolayan, 2004; Kang'ethe, 2013).

\subsection{Use of local languages as an easier way of mainstreaming HIVIAIDS messages}

Globally, languages form an integral component of culture in any society. Botswana is one of the countries which have succeeded in having one acceptably recognised language to conduct its national businesses. Even though the official working language is English, this is only in papers. Batswana widely use Setswana to do most of their businesses. This has an advantage to many aspects of development. This is why the acknowledged language scholar, Prof Ali Mazrui has hailed Botswana and South Africa for their adequate integration of their languages into development (Mazrui, 1996). In the HIVIAIDS campaign in Botswana, this has been an asset because majority or $90 \%$ of the Batswana speak and communicate in Setswana with ease. With the use of Setswana, the HIVIAIDS campaigners do not face significant language barrier in virtually all the corners of the country. Language, therefore, being an important aspect of culture can be an asset in the HIVIAIDS campaign message mainstreaming and dissemination. To this end, the National AIDS Coordinating Agency (NACA) is doing well in spreading Setswana based information, education and communication 
HIVIAIDS messages (GOB, 2009a). However, parliament has accepted the acknowledgement of a few indigenous languages such as Bayei, Hambukush, Basarwa and the need to have their languages integrated into the national school curriculum (Ramahobo, 1996, 1998).

In the same vein, it is this author's opinion that South Africa should exploit its language diversity and democracy for the benefit of the HIVIAIDS campaign. With eleven languages having attained official status, this if exploited can be an opportunity for the majority South Africans to be mainstreamed HIVIAIDS messages with ease. Statistics from South Africa (2003) indicates that some 25 languages are used in South Africa on a daily basis by more than 44.8 million people. There is also a revelation that the majority of South Africans, almost $80 \%$ of the population use an African language as their home language (Statistics South Africa, 2003).

\section{Perfidious Aspects of Cultures Detrimental to STIs and HIVIAIDS Prevention}

\subsection{Introduction}

Cultures can also be detrimental to the HIVIAIDS prevention when they weaken the forces or efforts of prevention of STIS and HIVIAIDS. The following aspects of culture have largely been perfidious as they: encourage gender inequality making women's negotiation for safer sex practices with men difficult; encourage the use and profound belief in unscientific and untested therapies; discourage or weakens the use of modern prevention methodologies such as the use of condoms; condone risky practices such as wife inheritance; strengthens some religions that are against the use of ARVs; offer an opportunity for traditional medical practitioners to hide under the cultural lenses to give misleading messages on ways to tackle HIVIAIDS.

\subsection{Cultural forces strengthens patriarchy that impedes the process of gender equality and equity}

Patriarchy means the power of male domination against women and children as bestowed by most traditional beliefs, practices and customs (Lekoko, 2009). Infact, the concepts of patriarchy and culture are phenomena that are interwoven as well as inextricably linked to one another. Patriarchy presents aspects that are diametrically opposed to women empowerment dispensation making prevention efforts like negotiating for safer sex methodologies a daunting task. This poses a big challenge to STIs and HIVIAIDS prevention.

\subsection{Cultures strengthening beliefs in unscientific and untested medical therapies}

Since cultures present themselves as mirrors of the societies and communities, it has become difficult to wish away some of its retrogressive phenomena that are richly grounded (Kang'ethe, 2009a). It remains an incontrovertible fact that the use of traditional therapies has been recorded in human history; and is still prevalent today despite the advent and increased prevalence of the modern biomedical therapies. To this end, the World Health Organization (WHO) estimates that at least a third of people in Africa do not have access to essential medicines making its people to depend on traditional medicines, whose safety and effectiveness has not been well documented (UNAIDS, 2000; Kang'ethe, 2009b). The use of these therapies are integrated as well as reinforced by the traditional cultures. Cultures make the users blind making it difficult to dissuade them from use despite their proven shortcomings (Kang'ethe, 2009b).

However, mitigating the impacts of HIVIAIDS has largely called for a scientific examination of most of the traditional therapies. This is especially because of empirical revelations of some traditional therapists peddling untruthful information to people living with HIVIAIDS regarding their diagnosis; leading to some HIVIAIDS clients getting worse or even dying. Correcting such information has not been easy, as traditional medical therapies have been deeply interwoven with the fabrics of culture (Kang'ethe, 2009b)

\subsection{Cultures discouraging the use of modern prevention methodologies such as condoms}

Although countries are today slowly winning the battle against cultures that discourage the use of contraceptives such as condoms, we still have grey areas in which cultural factors are so strong to an extent that the use of contraceptives is being shunned or discouraged. The many cases of people living with HIVIAIDS on ARVs in Botswana succumbing to repeated pregnancies forms suspicion of possible cultural pressures from their partners and society in general against the use of prevention contraceptives (NHASORC II, 2010). As a HIVIAIDS campaign measure in Botswana, people living with HIVIAIDS are being advised to avoid repeat pregnancies for their health's safety; and that a doctor's advice on the 
phenomenon is critical. The issue also poses health challenges as well as has some socio-economic dimensions especially if the coming child is also infected (Kang'ethe, 2007). In such a context, the cultural meaning attached to the desire to have children greatly discourages the use of contraceptives leaving the parties concerned vulnerable to STI and HIVIAIDS (Kang'ethe, 2007; NHASORC II, 2010).

\subsection{Cultures condoning risky practices such as wife inheritance}

it needs to appreciated that cultures are dynamic and that one aspect of culture that could be a panacea in one moment in history could be perfidious in another period of time (Adler, 1983). In many African communities, one's death did not have to stop the growth of his/ her family. Such a situation allowed the family members assign a brother to take the wife of his deceased brother; and in some cases, a sister will take the place of her deceased sister to continue the family. That has been a culture among some tribes in the western part of Kenya (Buckley, 1997). It is believed this could be one of the reasons why the region could be having higher HIVIAIDS prevalence than the national average (Buckley, 1997). The culture of wife inheritance is also prevalent among some communities in Zimbabwe (Jackson, 2002). With the advent of HIVIAIDS, this has been found to pose immense risks. In case of a living brother inheriting the wife of his deceased brother, the living brother could be at risk of contracting any contagious disease such as HIVIAIDS which may have led to the death of his brother. In equal measure, a sister who takes the place of her deceased sister risks being a target of the disease that caused the death of her sister. It is therefore a very risky cultural practice that should be avoided at all costs (Buckley, 1997; Jackson, 2002).

\subsection{Cultures strengthening some religious norms that compromise modern prevention efforts}

Religion offers a platform of hope for the present and the future. It is contained and sustained by an array of faith and religiously ordained practices (Byamugisha, Steintz, Williams \& Zondi, 2002). Many of the African Traditional Religions (ATR) or indigenous churches in Botswana have integrated cultures into their faith systems, making religious, medical and social interpretations of phenomenon culturally influenced. For instance, some of these churches believe in traditional healing therapies that differ from the modern prevention methodologies. Some subscribe to a plethora of beliefs about health and well-being with a central association of death and ill-health with ancestral retribution and/or witchcraft, and the observance of rituals meant to gain favour and protection by the ancestors from all forms of adversity including HIV and AIDS (Afolayan, 2004; Jackson, 2002).

In recent years, the government of Botswana has been battling with members of the Bazezulu church to accept their children's immunisation against diseases such as polio. The same religious thinking has not favoured their response to HIVIAIDS campaign on prevention. Most members of the Bazezulu community do not believe in modern day education which may be pivotal to development and understanding issues of prevention (Kang'ethe \& Gaseitsiwe, 2012).

\subsection{Traditional medical practitioners hiding under the lenses of culture to give misleading messages on HIV/AIDS.}

Despite their importance in the medical fraternity in general, some empirical revelations hold that traditional therapists are not professionally placed to handle HIVIAIDS (Kang'ethe, 2009b). Some researches on the traditional therapists and the modern biomedical practitioners reveal conflict between the two, each accusing the other for failure to recognize the potency and effectiveness of the other party (Kang'ethe, 2010). By and large, people's faith in traditional practitioners has been both historical and cultural. Empirical research in Tsabong, Botswana, in 2008 indicated that HIVIAIDS clients and community members had immense faith and trust in the healers, despite healers' validated shortcoming in the face of HIVIAIDS. It is this researcher's contention that the traditional therapists have been shielded by cultural curtains and thus obscuring their professional shortcomings (Kang'ethe, 2010).

\subsection{The cultural of multiple and concurrent partnership (MCP) compromising STI/HIV/AIDS prevention}

Although the practice of the culture of multiple and concurrent partnership is slowly waning away, especially due to the constitutional disregard in many countries with regard to a second marriageable partner, the ideology appear to be clandestinely going on, with both women and men knowingly practicing the norm. To this end, the Government of Botswana (GOB, 2009b) has acknowledged the prevalence of multiple and concurrent partners as one of the biggest behaviour dispensation that need to be addressed through behaviour modification process. In Botswana, the practice of multiple and concurrent partners can be traced from its cultures that traditionally condoned the practice. This finds 
evidence in the meanings of the following Setswana proverbs indicated by Kang'ethe (2009a):

"monna ga a agelwe lesaka" that loosely translates that a man should not be tied to one woman;

"monna ke selepe, o a hapaanelwa" "monna ke selepe, o a tsamaya o a rema" that, loosely translates that a man has liberty to associate with multiple and concurrent partners;

"monna ga o botswe kwa otswang teng" that loosely translates that a man should not be asked where he passed the night.

This author, formerly a temporary resident of Botswana but now resident in South Africa bears witness that even though some government policy makers in the HIVIAIDS campaign are of the opinion that the impact of these proverbs is insignificant, many adults as well as the youth know these proverbs. It is then no wonder a fact to say that the cultural hangovers continue to give people an open slate to advance what they feel had been allowed by their ancestors. However, these cultural aspects need to be fought vigorously to mitigate the effects of HIVIAIDS (GOB, 2009b).

\section{Conclusions/ Recommendations}

- It is critical that different countries' cultural rites of passage are adjusted to include prevention agenda in their programmes. This can be done without necessarily changing the cultural goal posts and meaning of the rites.

- The government, NGOs and civil society bodies should fight strongly through advocacy and lobbying against cultural practices such as wife inheritance that appear to derail the HIVIAIDS prevention strategy.

- It is absolutely necessary to forge a strong collaborative front between traditional therapists and the modern biomedical practitioners. This is to strengthen prevention of STI and HIVIAIDS.

- Governments, NGOs and campaign friendly bodies should strengthen education to the traditional healing practitioners to make their therapies hygienic and prevention friendly.

- Societies should identify and exploit the social capital in languages and use it to expedite prevention and message dissemination.

- The government should recognize the role of traditional leaders in making societies cohesive making it possible to mainstream important messages such as the need for circumcision

- Societies should urge their cultural religious leaders to accept the modern therapeutic systems in tandem with the culturally grounded treatment methodologies.

\section{References}

Adler, N.J. (1983). Cross Cultural Management Research: The Ostrich and the Trend. Academy of Management Review, 1983.Vol 8, no 2, page 226-232.

Afolayan, F. (2004). Culture and customs of South Africa.Westport, Connecticut, London.Greenwood Press.

Buckley, S. (1997). Wife inheritance spurs AIDS rise in Kenya. Washington Post Foreign Service. Saturday, November 8, 1997.

Byamugisha, G., Steinitz, L.Y., Williams, G., \& Zondi, P. (2002). Journeys of Faith. Church based responses to HIV and AIDS on three Southern African countries.G \& A Williams, Oxford, U.K.

Campbell, A., Robbins, L. \& Taylor, M. (eds) (2010). Tsodilo Hills: Copper Bracelets of the Kalahari. East Lansing \& Gaborone, Michigan State University Press \& The Botswana Society, 2010, Paper back, 178pages, ISBN: 198-9991244-19-8.

DMSAC Report. (2005). District multi-sectoral AIDS committee report presented in November, 2005 at Rural Adminstration Centre (RAC) Council Chambers.

Fisher, J.D \& Fisher, W.A,(2000). Theoretical approaches to individual level change in HIV risk behaviour. handbook of HIV prevention. AIDs Prevention and Mental Health, 2000. Pp3-55

Government of Botswana (GOB). (2009a).The Second Botswana National Strategic Framework for HIV and AIDS 2010-2016. Government Printers. Gaborone.

Government of Botswana (GOB). (2009b). Botswana Second Generation HIV Antenatal Sentinel Surveillance Technical Report. Government Printers. Gaborone

Jackson, H. (2002). AIDS AFRICA. Continent in crises. Safaids, Avondale, Harare, Zimbabwe.

Kang'ethe S.M. (2009b).Traditional healers as caregivers to HIVIAID patients. Sahara Journal.Vol 6 (2). September, 2009. pp 83-91.

Kang'ethe, S.M \& Gaseitsiwe, B.( 2011).Religious Education for Form Three.Gaborone. Botsalano Publishers.

Kang'ethe, S.M \& Rhakudu, M. (2010).Religious Education book for form 2. Gaborone. Heinemann Publishers.

Kang'ethe, S.M. (2006). Contribution of Caregivers in Community Home Based Care Programmes: The case of Kanye, Botswana. Unpublished PhD Dissertation in Social work, Department of Social Work, Faculty of Social Sciences, University of North West.

Kang'ethe, S.M. (2007). Beware of narrow agendas. Botswana Guardian Newspaper,3rd August, 2007 page 8 \& 9.

Kang'ethe, S.M. (2009a). "Inadequate Male involvement in Health Issues: The cause of gender skewed HIV and AIDs situations in Botswana". In Maundeni, T, 
Osei-Hwedie, B.Z., Mukaamambo, E. \&Ntseane, P.G. (eds). Male Involvement in Sexual and Reproductive Health. Prevention of Violence and HIVIAIDS in Botswana. Made Plain communications, Cape Town.

Kang'ethe, S.M. (2010). Attitudes to ARV access and factors undermining HIVIAIDS prevention. Lessons from the 2008 Tsabong stigma case study (Botswana).Social Work/MaatsakaplikeWerk2010: 46 (xx).Pp 433-449.

Kang'ethe, S.M. (2013).The panacea and perfidy of cultural rites of circumcision in African countries: Examples from Kenya, Botswana and South Africa. A literature review. EASSRR, Vol. XX1X, NO 1. January, 2013. Pp107-123.

Lekoko, R.N. (2009). A generation in jeopardy. Sexually active women in partriarchal settings and HIV and AIDS. In: Maundeni T, OseiHwedie BZ, Mukaamambo E, Ntseane PG, editors. Male involvement in sexual and reproductive health. Prevention of violence and HIVIAIDS in Botswana.Cape town: Made Plain Communications; 2009. p. 91-104.

Mathangwane, J.T. (2009). Bakalanga Traditional music: Some cultural insights. Botswana Notes and Records, Vol 41, 2009. P83-94

Mazrui, A. (1996). "Perspective: The Muse of Modernity and the Quest for Development." In Philip Altbach and Salah Hassan, eds., The Muse of Modernity: Essays on Culture as Development in Africa. Trenton: Africa World Press.

Mogogi K. (2001). Youth and culture of Peace. A paper presented at UNESCO Conference at Grand Palm Hotel, 16th February.Gaborone.

National AIDS Coordinating Agency (NACA). (2005). Botswana Second Generations HIVIAIDS Surveillance. Technical Report, Gaborone.

National HIVIAIDS/STI/ORID Research Conference II (NHASORC II). (2010). Research Partnerships and capacity Development. Summary Report.19th-21st May 2010.Gaborone.

Nyati-Ramahobo, L. (1998). Language, culture and learning: The missing link in teachereducation. In C.D. Yandila, P. Moanakwena, F.R. O'Mara, A.M.

Kakanda and J.Mensah (eds): Improving Education Quality for Effective Learning: The Teacher's Dilemma (pp. 207-14). Gaborone: Ministry of Education.[Proceedings of the Third Biennial Teacher Education Conference]

Nyati-Ramahobo,L.(1996). Challenges for improving literacy in Botswana. Mosenodi: Journal of the Botswana Educational Research Association 4 (2), 49-55.

Peltzer, K, Nqeketo, A., George, P., \& Xola, K. (2008). Attitudes of pre-initiates towards traditional male circumcision in the context of HIVIAIDS in the Eastern Cape, South Africa. Journal of Social Behaviour and Personality, September 1, 2008.

Ramphele, M. (2008). Laying Ghosts to Rest. Dilemmas of the Transformation in South Africa. Cape Town: Tafelberg. Statistics South Africa. (2003). Census in Brief. Pretoria: Statistics South Africa.

UNAIDS. (2000).collaboration with traditional healers in HIVIAIDS prevention and care in Sub -Saharan Africa. A literature Review, Geneva, Switzerland.

TAC (Treatment Action Campaign). (2007). 'Government Leadership on HIV/AIDS Irerevocably Defeats Denialism!Implement a New Credible Plan with Clear Targets!'Available at http://www.tac.org.za/AIDSDEnialismlsDead.html. (Accessed on 22 ${ }^{\text {nd }}$ February 2007). 